\title{
EDUCAÇÃO INCLUSIVA E OS DESAFIOS PARA FORMAÇÃO DE DOCENTE
}

\author{
LA EDUCACIÓN INCLUSIVA Y LOS DESAFÍOS PARA LA FORMACIÓN DE \\ PROFESORES
}

INCLUSIVE EDUCATION AND THE CHALLENGES FOR TEACHER FORMATION

José Jailton RIBEIRO ${ }^{1}$

\begin{abstract}
RESUMO: O presente artigo tem como objetivo identificar e analisar, algumas peculiaridades a respeito da educação inclusiva, focando no aluno autista e na formação docente, e suas práticas pedagógicas. Pretendemos também investigar pressupostos da educação no Brasil, fazer uma explanação a respeito das práticas pedagógicas utilizadas nas salas de aulas com alunos autistas, elucidar a importância em se ter uma formação pedagógica em educação especial para e trabalhar com alunos com autismo ou com outro tipo de deficiência. Identificar o perfil do docente para atuar com as diferentes deficiências. Fundamentar o processo histórico da educação especial no Brasil professor, diante das diversas mudanças sociais ocorridas.
\end{abstract}

PALAVRAS-CHAVE: Educação inclusiva. Autismo. Ensino regular.

RESUMEN: Este artículo tiene como objetivo identificar y analizar algunas peculiaridades de la educación inclusiva, centrándose en la formación de los estudiantes y profesores autistas y sus prácticas pedagógicas. También pretendemos investigar los supuestos de la educación en Brasil, hacer una explicación sobre las prácticas pedagógicas utilizadas en las aulas con estudiantes autistas, para dilucidar la importancia de tener una formación pedagógica en educación especial para y trabajando con estudiantes con autismo u otro tipo de discapacidades. Identificar el perfil del profesor para actuar con las diferentes discapacidades. Para fundamentar el proceso histórico de la educación especial en el Brasil como maestro, en vista de los diversos cambios sociales que se han producido.

PALABRAS CLAVE: Educación inclusiva. Autismo. Educación regular.

ABSTRACT: This article has the objective to identify and analyze some peculiarities regarding inclusive education, focusing on the autistic student and the teacher formation and pedagogical practices. We also intend to investigate education assumptions in Brazil, making an explanation about the teaching methods used in the classroom with autistic students, elucidate the importance of having an educational background in special education and working with students with autism or other type of disabilities. Identify the profile of teachers to work with different disabilities. Substantiate the historical process of special education teacher in Brazil, given the different social changes.

${ }^{1}$ Universidade Federal do Rio Grande do Norte (UFRN), Natal - RN - Brasil. Supervisor do programa PIBID da graduação em Pedagogia e Professor Efetivo da Rede Municipal da Educação Básica. Graduação em Pedagogia (FACEX). Especialização em Psicopedagogia (UNINASSAU). MBA em Gestão Estratégia de Pessoa (LERGN). ORCID: https://orcid.org/0000-0003-4391-6310. E-mail: josejailtonnribeiro@ gmail.com 
KEYWORDS: Inclusive education. Autism. Regular education.

\section{Introdução}

A inclusão é um direito que tem sido muito discutido e polemizado pelos mais diferentes segmentos educacionais e sociais. No entanto, inserir alunos com deficiência em sala regular, especialmente aqueles com autismo, tem sido um desafio.

O objetivo deste trabalho é discutir a respeito da educação inclusiva, focando no aluno autista e na formação docente. As práticas pedagógicas, à luz de alguns teóricos, devem compreender a Educação Inclusiva como um direito de todos e a necessidade de se promover a aprendizagem. Pretendemos também demonstrar a viabilidade da inclusão pela transformação geral das escolas com base em minhas experiências em sala de aula, visando atender aos princípios deste novo paradigma educacional.

A experiência em sala de aula tem convocado o docente a trabalhar na concepção da educação inclusiva com crianças, jovens e adultos como uma ação educacional humanística, democrática, amorosa, mas não piedosa, que percebe o sujeito em sua singularidade e que tem como objetivos o crescimento, a satisfação pessoal e a inserção social de todos.

A realidade no contexto escolar demonstra que é necessário ao docente refletir sobre a inclusão e uma prática que contribua para desenvolver o aluno nas suas potencialidades.

Percebemos que só se consegue atingir o objetivo de aprendizagem, quando a escola regular assume que as dificuldades de alguns alunos não são apenas deles, mas resultam em parte do modo como o ensino é ministrado e a avaliação concebida, pois não apenas as crianças portadoras de deficiência são excluídas, mas também aquelas que apresentam dificuldades no processo e não conseguem superá-las.

O sucesso da inclusão de nossos alunos com deficiência na escola regular privada decorre, portanto, das possibilidades de se conseguir progressos significativos desses alunos na escolaridade, por meio da adequação das práticas pedagógicas à diversidade dos aprendizes. Assim sendo, pergunta-se como o docente tem sido formado e se esta formação tem contribuído para o seu fazer pedagógico no dia-a-dia da sala de aula.

O Brasil demonstrou traços de uma política educacional inclusiva já na promulgação da Constituição Federal (1988), no título VIII, capítulo Da Ordem Social:

Art. 208. O dever do Estado com a Educação será efetivado mediante a garantia de: 
III - atendimento educacional especializado aos deficientes, preferencialmente na rede regular de ensino;

Art. 227:

II $\S-1^{\circ}$ criação de programas de prevenção e atendimento especializado para os deficientes físicos, sensorial ou mental, bem como de integração social do adolescente com deficiência, mediante o treinamento para o trabalho e a convivência, e a facilitação do acesso aos bens e serviços coletivos, com a eliminação de preconceitos e obstáculos arquitetônicos.

$\S 2 .^{\circ}$ A lei disporá sobre normas de construção dos logradouros e dos edifícios de uso público e de fabricação de veículos de transporte coletivo, a fim de garantir acesso adequado às pessoas com deficiência.

Diante do exposto podemos dizer que o nosso país vem avançando e reunindo esforços para assegurar o direito à Educação de qualidade, pois ainda faz parte de luta em prol da igualdade social, principalmente no que se refere a educação especial que, apesar de ter avançado, no Brasil ainda é precária. A obrigatoriedade determinada pelas conquistas legais não é garantia de permanência e avanços no desenvolvimento do aluno, apenas assegura o acesso ao ensino regular; o que representa um processo importante na história da inclusão.

O Brasil esteve em consonância com as propostas da conferência Mundial sobre Necessidades Educacionais Especiais em Salamanca (ESPANHA, 1994). Tais propostas denominadas DECLARAÇÃO DE SALAMANCA, tiveram a participação de delegados de 88 governos e 25 organizações internacionais e o objetivo de estabelecer princípios, políticas e práticas na área das necessidades educativas especiais. $\mathrm{O}$ documento oficial foi adaptado à terminologia educacional brasileira onde foi alterado o termo "necessidades educativas especiais" por "necessidades educacionais especiais" e da mesma forma, a expressão "integrada" ou "integradora" foi também substituída por "inclusiva". A expressão necessidades educacionais especiais é utilizada para referir-se a crianças e jovens cujas necessidades decorrem de sua elevada capacidade ou de suas dificuldades para aprender. Ela está associada, portanto, a dificuldades de aprendizagem, não necessariamente vinculada a deficiência(s).

As Necessidades educacionais podem ser identificadas em diversas situações representativas de dificuldades de aprendizagem, como decorrência de condições individuais, econômicas ou socioculturais dos alunos:

- crianças, jovens e adultos com condições físicas, intelectuais, sociais, emocionais e sensoriais diferenciadas;

- crianças, jovens e adultos trabalhadores ou que vivem nas ruas;

- crianças, jovens e adultos de populações distantes ou nômades;

- crianças, jovens e adultos de minorias linguísticas, étnicas ou culturais;

- crianças, jovens e adultos de grupos desfavorecidos ou marginalizados. 
Nesta perspectiva, a inclusão apresenta-se de forma ampla. No trato desse trabalho, estabeleceremos a discussão sobre a questão dos sujeitos com deficiência e transtornos globais.

A educação especial como modalidade da educação escolar ganha mais um dispositivo legal e político-filosófico a seu favor, a LDB n. 9.394/96, Lei de Diretrizes e Bases da Educação Nacional:

\begin{abstract}
Art. 58 - Entende-se por educação especial, para os efeitos desta Lei, a modalidade de educação escolar, oferecida preferencialmente na rede regular de ensino, para educandos com necessidades especiais.

$\S 1^{\circ}$ Haverá, quando necessário, serviços de apoio especializado, na escola regular, para atender as peculiaridades da clientela de educação especial.

$\S 2^{\circ} \mathrm{O}$ atendimento educacional será feito em classes, escolas ou serviços especializados, sempre que, em função das condições específicas dos alunos, não for possível a sua integração nas classes comuns do ensino regular.

Parágrafo único. O poder Público adotará como alternativa preferencial, a ampliação do atendimento aos educandos com necessidades especiais na própria rede pública regular de ensino, independentemente do apoio às instituições previstas neste artigo. (BRASIL, 1996, capítulo V).
\end{abstract}

Através do censo escolar podemos observar o crescimento de $640 \%$ das matrículas do ensino especial em escolas regulares/classes comuns de 1998 a 2006, resultados claros do sucesso da política inclusiva no Brasil. Infelizmente o acréscimo ao representar número de inclusão no ensino, não indica assegurar a aprendizagem. Atualmente esta é a luta mais significativa para a educação inclusiva.

\title{
O aluno autista, a educação escolar em uma perspectiva histórico-cultural
}

Nos dias atuais, o aluno autista se enquadra nos laudos como transtornos Globais do Desenvolvimento (TGD). Esta classificação é utilizada para o seu diagnóstico, porque se faz necessário o agrupamento de alguns critérios estabelecidos pelo Manual Diagnóstico e Estatística de Transtornos Mentais (DSM-IV) 59 que é um (CID-10), Classificação Internacional de Doenças. Quando uma criança é diagnosticada ela deve apresentar comprometimento em três áreas principais: alterações qualitativas das interações sociais recíprocas; modalidades de comunicação; interesses e atividades restritos, estereotipados e repetitivos. No tocante, é importante considerar que existe uma heterogeneidade de comportamentos e atitudes entre os sujeitos com autismo. Nem todos os alunos com autismo, se comunicam mediante verbalização. Alguns aceitam o toque, enquanto outros rejeitam.

Os comportamentos estereotipados podem estar presentes ou ausentes. Essas situações tornam os indivíduos únicos e distantes do olhar congelado sobre o autismo. Assim, para além 
de discutir as causas do autismo ou características estereotipadas, torna-se necessário avançar no debate das possibilidades de conhecimentos desses sujeitos em suas singularidades e de ações educativas que favoreçam o desenvolvimento da criança com autismo.

Estudar o histórico da escolarização desses sujeitos pode contribuir para compreendermos o movimento pelo qual passaram desde a exclusão do ensino comum até chegar às ações que viabilizam sua inclusão escolar. Contextualizaremos brevemente a escolarização da criança com autismo, tomando como referência o período em que ela esteve excluída da escola até sua inserção neste espaço pela matrícula no ensino comum. Essa escolarização passou por mudanças que envolveram a saída das escolas especiais e a entrada no ensino comum. Contudo, essas mudanças não se efetivaram em um tempo curto, ao contrário, envolveram uma busca para ocupar um lugar na escola para todos, o que ainda não se configurou completamente na realidade brasileira.

O direito à educação para esses alunos está garantido na legislação nacional, através da Constituição Federal do Brasil de 1988 e pela Lei de Diretrizes e Bases da Educação Nacional LDB n $n^{\circ}$ 9.394/96, além de vários outros documentos legais. Porém, no cotidiano escolar, percebemos que esse direito legal necessita se materializar pela via da ação pedagógica dos professores e da implementação de políticas educacionais que favoreçam a inclusão escolar.

Muitas vezes, a articulação restrita das políticas educacionais e a precariedade das ações pedagógicas dificultam a incorporação das necessidades de aprendizagem desses estudantes nas atividades vivenciadas pelo grupo de uma sala regular, pois a visão clínica está evidenciada, projetando a ideia de que esses estudantes necessitam de intervenções "curativas" às suas "deficiências" em detrimento do acesso ao conhecimento trabalhado no coletivo da turma. Discorrendo sobre a educação escolar de sujeitos com autismo, Baptista, Vasques e Rublescki (2002) mencionam as propostas que enfocam o estabelecimento de comportamentos considerados adequados por meio de repetições e estratégias pouco flexíveis, as quais revelam uma percepção desses sujeitos como incapazes de avanços significativos no desenvolvimento de processos de pensamento mais elaborados. Por outro lado, apoiando-nos na matriz históricocultural, entendemos que as relações sociais e a mediação pedagógica podem promover as condições necessárias ao desenvolvimento das funções psíquicas superiores em sujeitos com desenvolvimento atípico.

Para Vigotsky (2007), a história da sociedade e o desenvolvimento do homem estão totalmente ligados, de forma que não seria possível separá-los. Desde que nascem as crianças estão em constante interação com os adultos, que transmitem a elas sua maneira de se relacionar e sua cultura. 
É por meio desse contato com os adultos que os processos psicológicos mais complexos vão tomando forma. O desenvolvimento infantil está relacionado com as experiências mediadas que são oportunizadas no nosso convívio social. Segundo Vygotsky (2002), a formação da consciência e o desenvolvimento cognitivo ocorrem do plano social para o individual, seguindo um processo de apropriação, não de forma mecânica, mas impregnado pela ação do outro e do sujeito, num movimento dialético. Esse processo de apropriação possibilita a construção do conhecimento e da cultura e implica uma atividade mental perpassada pelo domínio de instrumentos de mediação do homem com o mundo. Entre esses elementos mediadores, encontra-se a linguagem. Para o autor, “[...] o pensamento e a linguagem são a chave para a construção da natureza da consciência humana”(VYGOTSKY, 2002, p. 61).

De acordo com Saviani (2008, p. 13), a essência do trabalho educativo consiste no “[...] ato de produzir, direta e intencionalmente, em cada indivíduo singular, a humanidade que é produzida histórica e coletivamente pelo conjunto dos homens". E nesse sentido, ressaltamos a necessidade de aprofundar a discussão sobre práticas educativas que viabilizem a apropriação, por parte de todas as crianças, especialmente aquelas com autismo, dos conhecimentos, valores, modos de pensar, de sentir e de agir que lhes permitam se constituírem na perspectiva da humanidade histórica e coletivamente produzida pelo conjunto dos homens.

\section{A formação docente}

Segundo Paro (1988, p. 258) tem sido unânime a insatisfação de gestores, pesquisadores e professores com as formas convencionais de se formar professores em nosso país. Realizados em dois níveis de ensino - Médio e Superior -, os atuais cursos não dão conta de preparar o professor com a qualidade que se exige hoje desse profissional.

A formação dos professores da educação básica (Educação Infantil, Ensino Fundamental e Médio) apresenta-se com fragilidades, apesar dos investimentos já realizados. No processo reflexivo vimos que ainda é necessário desenvolver competências e habilidades favoráveis ao desenvolvimento de uma prática pedagógica que possibilite a aprendizagem.

Historicamente, a formação de professores do ensino regular tem sido questionada, considerando que os resultados apontam esgotamento nos sistemas de Educação Brasileira.

Algumas mudanças no novo cenário da formação de professores foram percebidas após décadas de 90, em especial através da LDB 9.394/96, algo que aponta para a urgência de um posicionamento quanto à formação dos professores como profissionais mais preparados para a educação, é uma realidade que envolve não apenas o aluno da educação Especial. As mudanças 
são necessárias e com isso passam a existir inovações curriculares - interdisciplinaridade, salaambiente, ciclos de aprendizagem, dentre outras coisas - que requerem dos professores novas competências e conhecimentos para nossa atuação profissional e, como consequência, surgem novos saberes pedagógicos, que quase sempre não tiveram lugar em nossa formação.

É preciso, pela especialidade da deficiência e da próprio ser humano, que se tenha um curso específico para formar professores preparados para a atividade docente que possam construibuir nas transformações de concepções, na construção do saber; resultando assim na necessidade de se repensar a intervenção pedagógico-didática na prática escolar.

Soares $(1996 ; 1997 ; 1998)$, fala sobre a importância do investimento na qualidade da formação dos docentes e no aperfeiçoamento das condições de trabalho nas escolas, para que estas favoreçam a construção coletiva de projetos pedagógicos capazes de alterar os quadros de reprovação, retenção e da qualidade social e humana dos resultados da escolarização.

Com tantas mudanças e evoluções, a contribuição da LDB, é notório que o cenário educacional vem tendo uma ascensão de forma tímida nos processos pedagógicos nas escolas públicas e privadas, principalmente no que se refere a educação inclusiva.

\section{O professor que queremos}

Nos dias atuais e em nossa sociedade contemporânea, as rápidas transformações ocorrem no mundo do trabalho, o advento tecnológico vem se configurando como uma sociedade virtual e os meios de informação e comunicação incidem na escola de forma positiva.

Silva (1999, p. 260) afirma que não se ignora que esse desafio precisa ser, prioritariamente, enfrentado no campo das políticas públicas. Todavia, não é menos certo que os professores são profissionais essenciais na construção dessa nova escola.

Já de acordo com Ramalho (2004, p. 23):

Assumir a reflexão, a crítica, a pesquisa como atitudes que possibilitam ao professor participar na construção de sua profissão e no desenvolvimento da inovação educativa, que norteia a formação de um profissional não para compreender e explicar os processos educativos dos quais participa, como também para contribuir na transformação da realidade educacional no âmbito de seus projetos pessoais e coletivos.

Todo desenvolvimento profissional envolve formação inicial e contínua articuladas a um processo de valorização identitária e profissional dos professores. Identidade que é epistemológica, ou seja, que reconhece a docência como um campo de conhecimentos específicos configurados em quatro grandes conjuntos, a saber, conteúdo das diversas áreas do 
saber e do ensino, ou seja, das ciências humanas e naturais, da cultura e das artes; conteúdos didático-pedagógicos (diretamente relacionados ao campo da prática profissional), conteúdos relacionados a saberes pedagógicos mais amplos (do campo teórico da prática educacional e conteúdos ligados à explicitação do sentido da existência humana individual), sensibilidade pessoal e social, considera, assim, que as transformações das práticas docentes só se efetivam na medida em que o professor amplia sua consciência sobre a própria prática, a da sala de aula e a da escola como um todo, o que pressupõe conhecimentos teóricos e críticos sobre a realidade.

Com isso entendemos que existem consequências, valorizar nosso trabalho como docente significa dotar os professores de perspectivas de análise que os ajudem a compreender os contextos históricos, sociais, culturais, organizacionais nos quais se dá sua atividade docente. Em síntese, dizemos que o professor é um profissional do humano que: ajuda o desenvolvimento pessoal/intersubjetivo do aluno; um facilitador do acesso do aluno ao conhecimento (informador informado); um ser de cultura que domina de forma profunda sua área de especialidade.

O profissional da educação deve ser formado nas universidades, não deixando que exista uma dicotomia entre teoria e pratica pedagógica como, também, havendo uma contextualização com o conhecimento prévio, que é o lugar da produção social do conhecimento, da circulação da produção cultural em diferentes áreas do saber e do permanente exercício da ação e reflexão do saber pedagógico.

Em nossa contemporaneidade, ou seja, as primeiras décadas do século XX, vivem-se momentos de necessidade de renovação em todos os setores da sociedade, observa-se isso também na área da educação, assim como reflexão para práticas mais eficientes e eficazes.

Não podemos deixar de falar em educação de qualidade sem mencionar uma formação continuada de professores; que já vem sendo considerada, juntamente com a formação inicial, uma questão fundamental nas políticas públicas para a educação. Entendemos que o professor precisa também estar preparado para os novos desafios desta geração, que está sempre em contato com novas tecnologias e fontes de acesso ao conhecimento instantâneo.

É notório que, além disso, em sua formação inicial, possivelmente, existiram alguns aspectos deficitários, pois no passado não havia nenhuma disciplina que contribuísse para o entendimento da educação especial. O professor polivalente passa a adquirir os conhecimentos após LDB que traz no seu teor a necessidade de mudança curricular. 
A formação continuada não se esgota somente em um curso de atualização, mas deve ser encarada como um processo, construído no cotidiano escolar de forma constante e contínua (CUNHA; KRASILCHIK, 2000, p. 3).

O trabalho de pesquisa bibliografia nós permitiu perceber que a formação do professor vai além da aprendizagem de técnicas, conceitos e metodologias, requer um envolvimento maior com desenvolvimento curricular, planejamento e, em tese, a capacidade de solucionar problemas relacionados ao contexto escolar, em especial ao aluno autista, pois suas especificidades requerem conhecimentos teóricos profundos. Nos últimos dez anos foram inseridas algumas disciplinas para discutir a educação inclusiva nas licenciaturas. A determinação da lei e as mudanças sociais com relação a inserção do aluno com deficiência no ensino regular e seu acesso são gradativamente ampliadas, e o ensino superior tem contribuído para a concretização das melhorias necessárias.

\section{Metodologia}

Segundo a conceitualização de Biderman (1998), metodologia é o estudo dos métodos a serem empregados ao se ensinar uma ciência ou uma arte, conjunto de métodos empregados em uma atividade. Portanto, com base neste contexto nos propomos a descrever o caminho realizado em nossa pesquisa.

A pesquisa foi elaborada através de levantamentos bibliográficos e consulta documental em bancos de dados oficiais, nos últimos 6 meses.

Sobre as bases de dados para o levantamento bibliográfico, a pesquisa na base da Biblioteca Virtual em Educação. Foi utilizada, busca na literatura científica e técnica da área de "Educação Especial”, cuja captação reúne as seguintes bases:

-Portal do MEC.

-Biblioteca da UFRN (Universidade Federal do Rio Grande do Norte).

-Scielo - Scientific Electronic Library Online: é um projeto consolidado de publicação eletrônica de periódicos científicos seguindo o modelo de Open Access, que disponibiliza, de modo gratuito, na Internet, os textos completos dos artigos de mais de 290 revistas científicas do Brasil, Chile, Cuba, Espanha, Venezuela e outros países da América Latina. Além da publicação eletrônica dos artigos, Scielo provê enlaces de saída e chegada por meio de nomes de autores e de referências bibliográficas. Também publica relatórios e indicadores de uso e impacto das revistas. 
O presente estudo utilizou os seguintes descritores, Educação Especial. Obtivemos uma quantidade total de 20 artigos e livros lidos, dentre os quais foi realizada uma triagem de 10 referências bibliográficas.

\section{Considerações finais}

Percebemos que muitos conhecem o conceito de Inclusão, embora o processo possa ser muito mais difícil de ser colocado em prática. Entendemos que as políticas públicas e as leis que permeiam esta trajetória envolvem esforços e habilidades, pois perpassa pela modernização e reestruturação de muitas condições existentes na maioria das escolas, sejam públicas ou privadas. Com isso enfrentamos muitos obstáculos para mudar as condições excludentes de ensino e aprendizagem dentro das Unidades de Ensino.

É notório que ainda temos um grande desafio, repensar os novos processos para inclusão de alunos independente da sua deficiência, em uma matriz arcaica de concepção escolar; daí a necessidade de se recriar o modelo educacional vigente. Compreendemos também que as escolas que reconhecem e valorizam as diferenças desenvolvem projetos educacionais inclusivos e o ensino que ministram difere do usual visando atender às peculiaridades dos educandos que não conseguem acompanhar seus colegas de turma.

É notório que as políticas de inclusão constituem, além de um grande desafio para o século XXI, uma oportunidade para a construção de um outro mundo, mais humano e mais justo, no qual todos possam viver em harmonia e de modo sustentável. A inclusão não é só uma política, mas um caminho que, ao trilhar, construímos.

Compreendemos também que o conhecimento sobre os alunos autistas precisa ser aprofundado e que o professor(a), em sua formação, deve ter a oportunidade de adquiri-lo, entendendo que no ambiente escolar poderá enfrentar dificuldades.

Segundo a literatura, a maioria dos autistas possuem diversas variações possíveis de inteligência, mas nem todos estão aptos à inclusão no ensino regular. Para este fim, dependemos de uma série de fatores e condições da escola inclusiva, presença de profissionais qualificados, para poder garantir todos os processos de ensino e aprendizagem da criança.

A escola se torna importante para o autista, pois um dos desafios é fazer com que eles conseguiam se socializar. Em alguns casos essa oportunidade não vem a contribuir significativamente, dependendo do seu nível de comprometimento, pois não entendem o mundo humano e social, casos em que eles necessitam de escolas especializadas. São aqueles cuja inteligência é mais comprometida e tem mais possibilidades de aprender em escolas mais 
preparadas, com diversos recursos pedagógicos específicos, para poder assim desenvolver aprendizagem.

Ao logo de nosso trabalho podemos concluir que os alunos autistas, necessitam, de forma fundamental, que a família e amigos os tratem normalmente, tentando entendê-los em sua forma de ser e assim tentar ajudá-los, propiciando tratamento em todas as áreas que precisem, sendo também fundamental a interação da escola e família de forma mais intensa para juntos possam contribuir de forma significativa em todos seus aspectos seja físico, motor, intelectual ou social.

\section{REFERÊNCIAS}

BAPTISTA, C. R. Integração e autismo: análise de um percurso integrado. In: BAPTISTA, C. R.; BOSA, C. A. (Orgs.). Autismo e educação: reflexões e propostas de intervenção. Porto Alegre: Artmed, 2002.

BRASIL. Lei n. 9.394, 20 de dezembro de 1996. Lei de Diretrizes e Bases da Educação Nacional. Diário Oficial da União, Brasília, 23 dez. 1996.

CUNHA, A. M. O.; KRASILCHIK, M. A formação continuada de professores de ciências: percepções a partir de uma experiência. In: REUNIÃO ANUAL DA ANPED, 23., 2000, Caxambu. Anais [...]. Caxambu, 2000.

PARO, V. Administração escolar. São Paulo: Cortez, 1988.

PLETSCH, M. D.; LIMA, M. F. C. A inclusão escolar de alunos com autismo: um olhar sobre a mediação pedagógica. In: SEMINÁRIO INTERNACIONAL INCLUSÃO ESCOLAR: práticas em diálogo, 1., 2014, Rio de Janeiro. Anais [...]. Rio de Janeiro: Instituto de Aplicação Fernando Rodrigues da Silveira - CAp-UERJ, 2014. Disponível em: https://docplayer.com.br/1588220-A-inclusao-escolar-de-alunos-com-autismo-um-olharsobre-a-mediacao-pedagogica.html. Acesso em: 02 jan. 2020.

RAMALHO, B. L. et al. Formar o professor, profissionalizar o ensino: perspectivas e desafios. 2. ed. Porto alegre: Sulina, 2008.

SAVIANI, D. Pedagogia histórico-crítica: primeiras aproximações. Campinas: Autores Associados, 2008.

SILVA, C. S. B. Curso de pedagogia no Brasil: história e identidade. Campinas: Autores Associados, 1999.

SOARES, M. A. L. A educação do deficiente auditivo: reabilitação ou escolaridade? 1990. Dissertação (Mestrado) - Pontifícia Universidade Católica, São Paulo, 1990.

VYGOTSKI, L. S. A construção do pensamento e da linguagem. 2. ed. São Paulo: Martins Fontes, 2000. 
VYGOTSKI, L. S. A formação social da mente: o desenvolvimento dos processos psicológicos superiores. 7. ed. São Paulo: Martins Fontes, 2007.

\section{Como referenciar este artigo}

RIBEIRO, José Jailton. Educação inclusiva e os desafios para formação de docente. Temas em Educ. e Saúde, Araraquara, v. 16, n. 1, p. 84-95, jan./jun., 2020. e-ISSN 2526-3471. DOI: https://doi.org/10.26673/tes.v16i1.13316

Submetido em: 13/01/2020

Revisões requeridas: $10 / 03 / 2020$

Aprovado em: 30/04/2020

Publicado em: 19/06/2020 